\title{
ANTI LEISHMANIAL ACTIVITIES OF SOME ANTIDEPRESSANT DRUGS, AND ANTIFUNGAL DRUGS.
}

\author{
Sagar S Trivedi ${ }^{1 *}$, Ms Geeta. N. Lodhi ${ }^{2}$, Dr. C.A. Doifode ${ }^{3}$, Harsha Raut ${ }^{4}$. \\ *1,2,3,4 Shri Sachhidanand shikshan Sansthan's Taywade College of Pharmacy, Koradi.
}

\section{*Corresponding Author: -}

\begin{abstract}
: -
Leishmanisis is wide range, worldwide, without drug, vaccine, secticide and has not sterile immunity and efforts in this field have not been successful.Leishmaniasis is a complex vectorborne disease caused by different species of Leishmania. It affects at least 12 million people worldwide. Leishmaniasis is commonly associated with poor economic conditions and immune compromised situations like HIV co infection. There is increasing in drug resistance to commonly used therapeutics as well as lack of vaccine program. This leads to a perpetual search for a new drug for leishmaniasis. This review fundamentally deals with some antidepressant drugs, and antifugal drugs showing the anti-leishmanial activities. The antidepressant drugs are Imipramine, Sertraline, Ketanserin and Mianserin. Imipramine being a Tri Cyclic Antidepressant (TCA) drug kills Leishmania donovani elevating IL-12/IL-10 ratio. Sertraline belonging to the selective serotonin reuptake inhibitor (SSRI) drugs, removes parasite loads from spleen and liver probably by declining cytoplasmic ATP consumption. Ketanserin is a serotonin receptor (5HT2A/2C) antagonist that kills both amastigotes and promastigotes probably due to inhibition of 3-hydroxy-3-methylglutaryl coenzyme A reductase (HMGR). Mianserin belonging to the TCA group of drug, kills both promastigote and amastigote parasites also probably due to the inhibition of HMGR. The present review will give the summarized information about putting some old antidepressant drugs for the treatment of another disease like Leishmania. Many topical antifungals have been available, two important antibiotics: amphotericin B to deal with systemic mycosis and griseofulvin to supplement attack on dermatophtes. A number of antifungal agents have been investigated in a rodent model for their parasiticidal activity against visceral leishmaniasis. These drugs have been administered intravenously both alone, and in conjunction with liposomes. All the compounds tested: griseofulvin, 5-fluorocytosine, and amphotericin B-together with the known antileishmanial drug pentamidinedisplayed enhanced therapeutic activity when given in liposomal form. In the case of amphotericin, liposomes composed of hydrogenated lecithin, or containing cholesterol or ergosterol in the membrane, were least toxic to the mammalian host, and had the highest therapeutic capability.
\end{abstract}

Keywords: - Antileishmania, Antidepressant, Antifungal.

\section{(우 (\$) (1)}




\section{INTRODUCTION}

Leishmaniasis is one of the most diverse and complex vector-borne metazoonosis diseases [1]. The causing agent is at least 17 species [2] of obligate intracellular protozoan parasites that belong to the genus Leishmania [3]. It is transmitted to human by the bite of phlebotomine female sand flies of the genera Phlebotomus and Lutzomyia in the old and new worlds respectively [4]. The species are in widespread tropical and subtropical continents except Antarctica [5]. The disease is endemic in 88 countries of Indian subcontinent, Southern Europe and Western Asia to America including rural and peri urban areis[6]. Leishmaniasis shows a disease burden of 12 million affected people with an annual estimation of 2-4 million new cases globally of which $60 \%$ cases occur in India alone[7].

Leishmaniasis is traditionally classified in three different clinical forms: Visceral Leishmaniasis (VL), Cutaneous Leishmaniasis (CL) and Mucocutaneous Leishmaniasis (MCL). This ranges from simple cutaneous ulcers to huge destruction in CL and subcutaneous tissues in ML. Other cutaneous manifestations are Diffuse Cutaneous (DCL), Recidivans (RL) and Post Kala-Azar Dermal (PKDL) Leishmaniasis. However, VL is the most complicated form of Leishmaniasis that can cause death if remain untreated.Leishmaniasis is a disease of poor mainly living in tropical regions of developing world. It is more seen in immunocompromised health conditions like HIV co-infection [8, 9]. Increasing drug resistance to commonly used drugs [sodium stibogluconate (SSG), Amphotericin B, Pentamidine or Miltefosine] [10-14], lack of effective vaccine program me [15] and difficulties in sustaining treatment procedure sharply demands for newer cost-effective orally used drugs. Perhaps, the search for a new drug is a perpetual process.

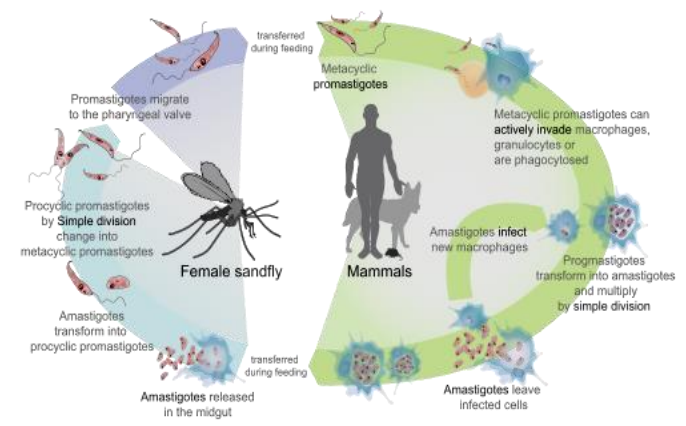

This review deals with encouraging antileishmanial activities of some antidepressant drugs, antifungal drugs.

\section{Antidepressants}

These are drugs which can elevate mood in depressive illness, Pratically all antidepressants affect monoaminergic transmission in the brain in one way or the other; and many of them have other associated properties. Over the past three decades, a large number of antidepressants with an assortment of effects on reptakelmetabolism of biogenic amines, and on prelpost-junctional aminergiclcholinergic receptors have become available so that a cogent classification is difficult. The following working classification may be adopted.[16]

\section{CLASSIFICATION}

1. Reversible inhibitors oh MAO-A(RIMAs)

Ex: moclobemide, clorgyline

2. Tricyclic antidepressant

a. A . $\mathrm{Na}+5$-HT reuptake inhibitors

b. Ex: Imipramine, amitriptyline, doxepin

c. B \}. predominantly NA reuptake inhibitors

d. Ex: Desipramine, Amoxapine

3. Selective serotonin reuptake inhibitors (SSRIs)

a. Ex:Fluoxetine, Fluvoxamine, paroxetine

4. Serotonin and noradrenaline reuptake inhibitors

a. Ex: Vealafaxine, Duloxetine

5. Atypical antidepressants

Ex:Trazodone , Mianserin

\section{Classification of Antidepressant drugs}

Classification of antidepressant drugs are based on their pharmacological action and/or structural configurations. Antidepressant drugs act as pre synaptic agents to target different neurotransmitter receptors, mainly serotonin receptors. Figure 1 shows broad classification of three fundamental types of antidepressant drugs; degradation inhibitors, storage inhibitors and reuptake inhibitors [17,18]. The list of commonly prescribed antidepressant drugs are shown in the Table1 of which four antidepressant drugs are showing encouraging results against Leishmaniasis[17,23]. These antidepressant drugs are Imipramine, Sertraline, Ketanserin and Mianserin. 


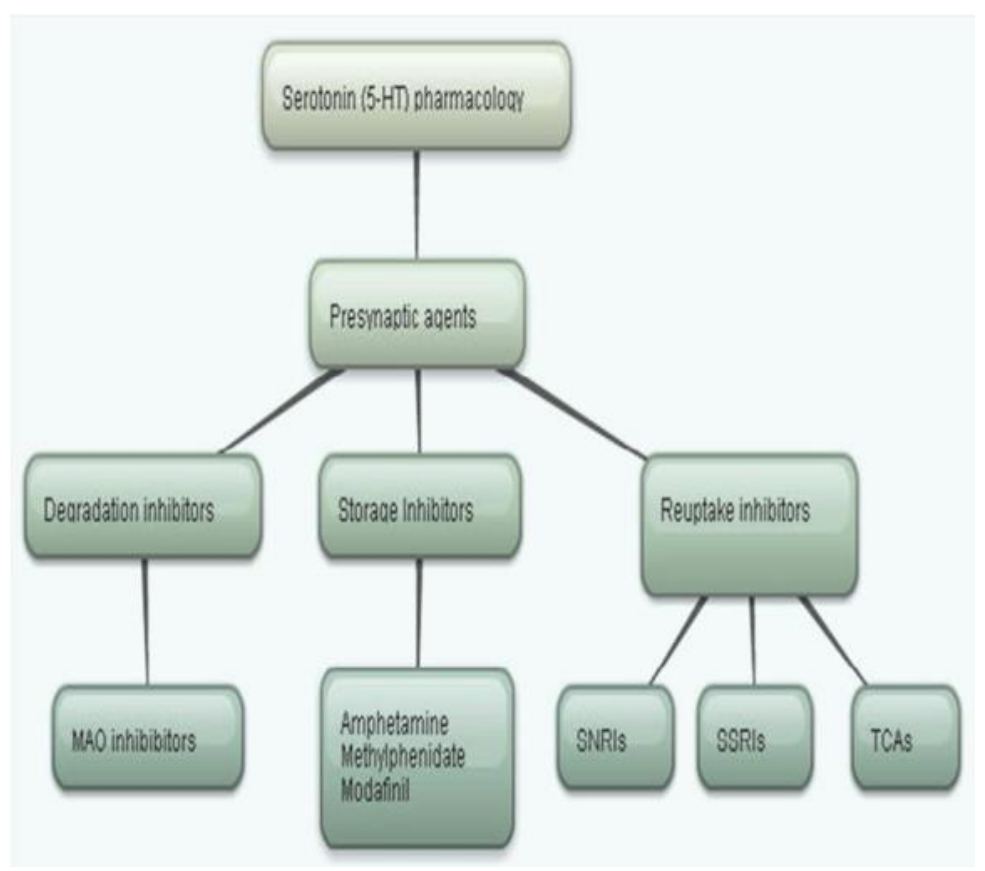

Figure 1: Major groups of antidepressant drugs

There are three major kinds of presynaptic agent's acts as antidepressant drugs; degradation inhibitors, storage inhibitors and reuptake inhibitors

Table 1. Major Groups of antidepressant drugs with examples of marketed compounds.

\begin{tabular}{|c|c|}
\hline Name of Antidepressant drug groups & Name of Antidepressant drugs \\
\hline Selective Serotonin Reuptake Inhibitor (SSRI*) & $\begin{array}{l}\text { Citalopram, Paroxetine, Escitalopram, } \\
\text { Fluoxetine, Fluvoxamine,Sertraline }\end{array}$ \\
\hline $\begin{array}{l}\text { Serotonin-nonepinephric } \\
\text { (SNRI*) }\end{array}$ & $\begin{array}{l}\text { Desvenlafaxine, Duloxetine, Levomilnacipran, } \\
\text { Milnacipran,Venlafaxine }\end{array}$ \\
\hline $\begin{array}{l}\text { Serotonin antagonistic and reuptake inhibitor } \\
\text { (SARI*) }\end{array}$ & \begin{tabular}{|lll} 
Etoperidone, Lubazodone, & Nefazodone, \\
Trazodone, &
\end{tabular} \\
\hline Norepinephrine reuptake inhibitor (NRI*) & Atomoxitine, Reboxetine, Viloxazine \\
\hline $\begin{array}{l}\text { Norpinephrine-dopamine reuptake inhibitor } \\
\text { (NDRI*) }\end{array}$ & Bupropion \\
\hline TAAR1* agonist & $\begin{array}{l}\text { Amphetamine,Dextroamphetamine, } \\
\text { Dextromethamphetamine,Lisdexamfitamine }\end{array}$ \\
\hline Tricyclic antidepressant $\left(\mathrm{TCA}^{*}\right)$ & $\begin{array}{l}\text { Amitriptyline, Butriptynine, Clomipramine, } \\
\text { Desipramine, } \\
\text { Imipramine,Iprindole, Lofepramine, Melitracen, } \\
\text { Nortriptyline, Opipramol, Protrityline, } \\
\text { Trimipramine }\end{array}$ \\
\hline Tetracyclic antidepressant $\left(\mathrm{TeCA}^{*}\right)$ & $\begin{array}{l}\text { Amoxapine, } \quad \text { Maprotiline, } \\
\text { Mirtazapine }\end{array}$ \\
\hline $\begin{array}{l}\text { Monoamine } \\
\text { Irriverssible: }\end{array}$ & \begin{tabular}{|lcr}
$\begin{array}{l}\text { Isocarboxazid, } \\
\text { ranylcypromine } \\
\text { Pirlindole }\end{array}$ & $\begin{array}{c}\text { Phenelzine, } \\
\text { reverssible }\end{array}$ & $\begin{array}{r}\text { Selegiline, } \\
\text { Moclobemide, }\end{array}$
\end{tabular} \\
\hline $\begin{array}{l}\text { Noradrenergic and specific serotonergic } \\
\text { antidepressant }\left(\mathrm{NaSSA}^{*}\right)\end{array}$ & Mianserin, Mirtazapine \\
\hline Serotonin Modulator and Stimulator (SMS*) & e, Vortioxetine \\
\hline Serotonin antagonist* & Clozapine, Ketanserin \\
\hline
\end{tabular}

Knowledge about serotonin receptor classes is needed to understand the underlying mechanism of actions of these antidepressant drugs. There are seven general serotonin receptor classes that include a total of fourteen known receptors [17]. A brief account about serotonin receptors are shown in Figure 2[18]. They are categorized in the Table-2 along with their subtypes, mode of action, functions, distribution [19,20]. 


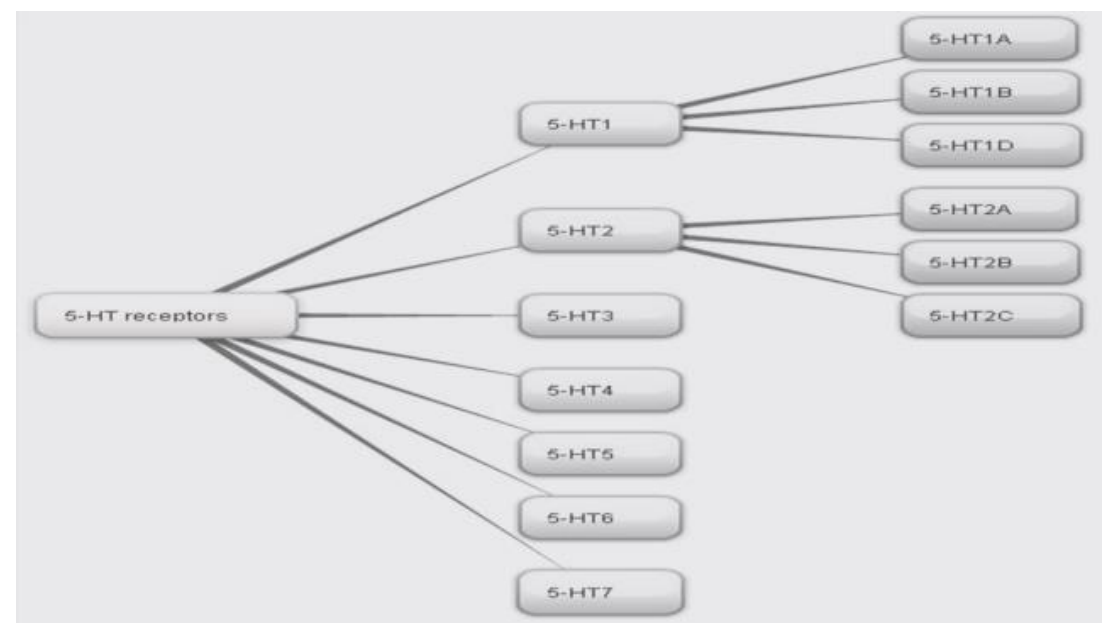

Figure 2: serotonin receptors

5-HT receptors: serotonin receptor family; 5-HT1-7: serotonin receptor subtypes; 5-HT1A-1D : 5-HT1 receptors subtypes; 5-HT2A-2C : 5-HT2 receptor subtypes.

Figure 2. Classification of serotonin receptors. Dermatophytosis is a common contagious disease caused by a fungus known as dermatophytes. Dermatophytes belong to three genera of Trichophyton, Microsporum, and Epidermophyton, which are able to break down keratin in tissues such as epidermis, hair, nails, feathers, horns, and hooves. There are various forms of this disease including tinea corporis, tinea pedis, tinea capitis, tinea barbae, tinea cruris, tinea manuum, and onychomycosis [1]. At present, there are several antidermatophyte drugs such as imidazoles and terbinafine for topical treatment and triazoles, griseofulvin, and terbinafine as oral antifungal for systemic treatment of dermatophytosis which have shown some problems including high toxicity, fungal resistance, and prolonged systemic therapy [1-3]. These factors express urgent needs for development of new effective treatment alternatives. Leishmaniasis is caused by parasitic protozoa of the genus of Leishmania transmitted by bites of phlebotomine sand flies [4]. It is still considered a major health problem in tropical and subtropical countries worldwide and its clinical symptoms are varied, ranging from simple cutaneous lesion to fatal disease [4, 5]. In Iran, both epidemiological forms of cutaneous leishmaniasis (CL) are present, Anthroponotic CL (ACL) and zoonotic CL (ZCL) caused by Leishmania tropica and Leishmania major, respectively [5, 6]. First choice treatment drugs, which are antimonials such as meglumine antimoniate and sodium stibogluconate, have limitations for being used due to the prolonged duration of treatment, high toxicity, and high emergence of resistant parasites against these drugs [7-9]. These factors render development of new effective antileishmanial drugs as a requirement. Since a long time ago, medicinal plants and their compounds have been important and valuable sources for treatment and prevention of diseases [10]. Barberry, Berberis vulgaris (family Berberidaceae), grows in Asia and Europe. B. vulgaris called "Zereshk" in Persian is native to south-east of Iran. Different parts of this plant including root, leaf, bark, and fruit have been widely used as folk medicine for treatment and prevention of various diseases including cardiovascular, gastrointestinal, respiratory, skin, renal, and infectious ones [11]. Previous studies have been carried out on chemical composition of $\mathrm{B}$. vulgaris and shown that the most important constituents of this plant are isoquinoline alkaloids such as berbamine, palmatine, and particularly berberine [12, 13]. So far, various studies have demonstrated antibacterial and antiparasitic effects of this plant against several pathogenic strains due to having berberine [14- 17]. Moreover, antifungal effect of B. vulgaris and its main component, berberine, against candida spp. has been discovered in some investigations $[18,19]$. In the present study, the in vitro antidermatophyte, antileishmanial, and cytotoxicity activities of various extracts of $\mathrm{B}$. vulgaris and its active principle, berberine, were described against Trichophyton mentagrophytes, Trichophyton rubrum, Microsporum canis, and Microsporum gypseum as pathogenic dermatophyte strains and Leishmania major and Leishmania tropica as parasitic

\section{ANTIFUNGAL}

Many topical antifungals have been available, two important antibiotics: amphotericin B to deal with systemic mycosis and griseofulvin to supplement attack on dermatophtes.

\section{CLASSIFICATION:}

1) Antibiotics

a) polyenes: amphotericin $\mathrm{B}(\mathrm{AMB})$, nystatin, hamycin, natamycin

b) heterocyclic benzofuran: griseofulvin

2) Antimetabolite: flucytosine (5-FC)

3) Azoles

a) Imidazoles (topical): clotrimazole, econazole.

b) Triazoles: fluconazole

4) Allylamine; terbinafine

5) Other topical agents: benzoic acid, undecylenic ACID 


\begin{tabular}{|c|c|}
\hline Drug & Mechanism of action \\
\hline \multicolumn{2}{|l|}{ Antimonials } \\
\hline $\begin{array}{l}\text { Sodium } \\
\text { Stibogluconate }\end{array}$ & $\begin{array}{l}\text { Unclear; probably by inhibition of -SH dependent } \\
\text { enzymes }\end{array}$ \\
\hline \multicolumn{2}{|l|}{ Diamidine } \\
\hline Pentamidine & $\begin{array}{l}\text { Interacts with kinetoplast DNA, inhibits } \\
\text { topoisomerase II, interferes with aerobic glycolysis }\end{array}$ \\
\hline \multicolumn{2}{|l|}{ Antifungals } \\
\hline Amphotericin B & $\begin{array}{l}\text { Bind with ergosterol of cell membrane of parasites } \\
\text { forming micopores and leakage of cellular content }\end{array}$ \\
\hline Ketoconazole & $\begin{array}{l}\text { Inhibiting conversion of lanosterol to ergosterol; } \\
\text { impairment of membrane function }\end{array}$ \\
\hline \multicolumn{2}{|l|}{ Others } \\
\hline Miltefosine & Trigger programmed cell death \\
\hline Paromomycin & $\begin{array}{l}\text { Action on ribosomes causing inhibition of protein } \\
\text { synthesis }\end{array}$ \\
\hline Allopurinol & Prototype of pyrazolopyrimidine, inhibits growth \\
\hline
\end{tabular}

Pathogenesis Of Leshminiasis

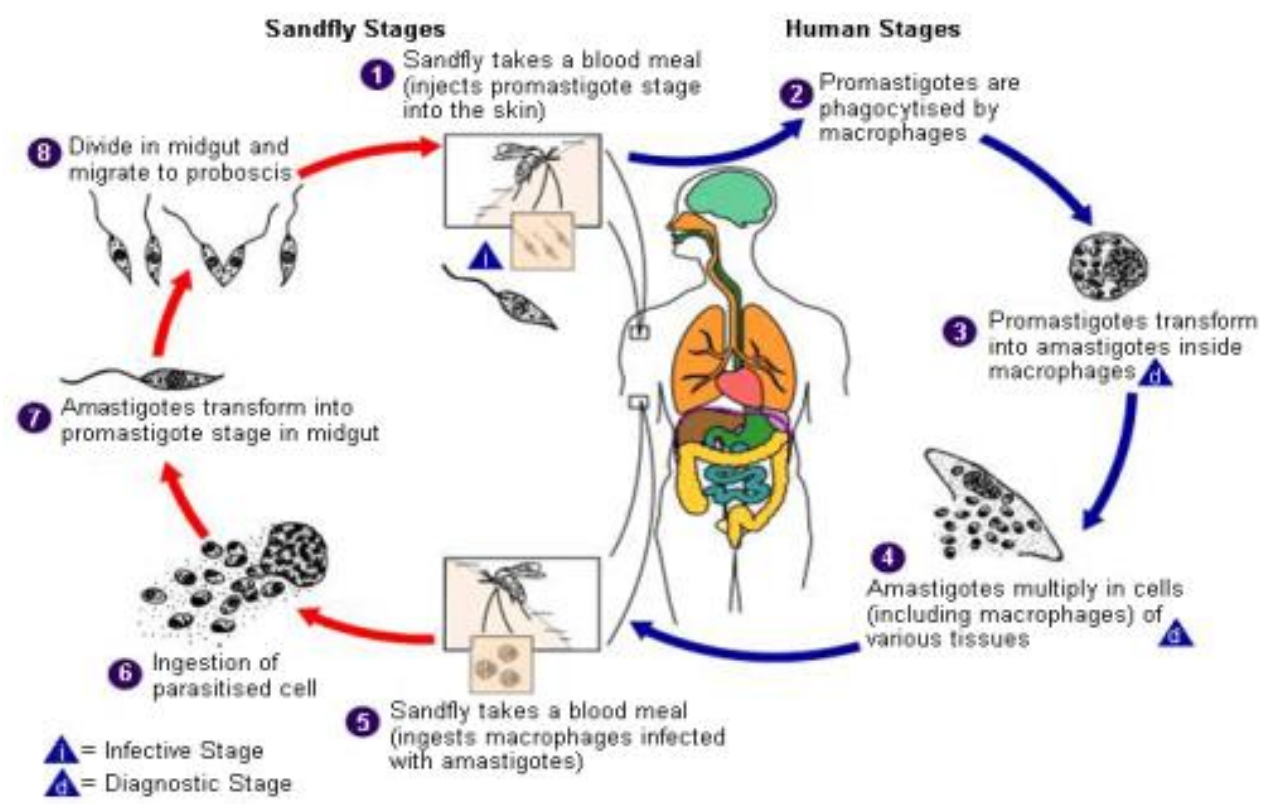

$>$ Sandfly Stages: Sandfly takes a blood meal injects promastigote stage into the skin.

$>$ Human stages: Promastigotes phagocytised by macrophages.

$>$ Promastigotes transform into amastigotes inside macrophages.

$>$ Amastigotes multiply in cells (including macrophages) of various tissues.

$>$ Sandfly takes a blood meal (ingests macrophages unfected with amastiogotes).

$>$ Ingestion of parasites.

$>$ Amastigotes transform into promatigotes stage in midgut.

$>$ Divide in midgut and migrate to proboscis.

\section{Antileishmanial Activities of the Antidepressant Drugs:}

Imipramine<smiles>CN(C)CCCN1c2ccccc2CCc2ccccc21</smiles> 
Imipramine $[\mathrm{N}$-( $\gamma$-dimethylaminopropyl)-iminodibenzyl HCL] is a TCA group of antidepressant drug and belongs to the broad

class of cationic amphiphilic drugs. Imipramine is Food and Drug Administration (FDA) approved drug, generally used for treatment

of depression and paediatric nocturnal enuresis [20]. It is also often used to treat chronic pain in combination therapy with other pain medications [20,21]. Mukherjee et al. [22] had chosen Imipramine for the therapy of experimental VL on the basis of the following previous observations:

i) The proton motive force of membrane of Leishmania donovani (LD) gets altered by the drug [23].

ii) The enzyme trypanothione reductase is upregulated in SSG resistant LD and Imipramine can inhibit this enzyme [24].

iii) TNF $\alpha$ is an important cytokine for antileishmanial defense and Imipramine can act as effective immune modulator by inducing its production [25].

iv) Cationic property of Imipramine helps in the absorption by phagocytic cells and accumulation in phagolysosomes [26].

v) Desipramine being the metabolite of Imipramine also effective against LD promastigotes [27]. Mukherjee et al. [22] reported that imipramine induced $60 \%$ apoptosis of LD parasites in comparison to Miltefosine which causes only $5.5 \%$ apoptosis. The decrease in mitochondrial trans membrane potential of Sodium Stibogluconate sensitive (SSGS) and resistant (SSG-R) LD promastigotes corroborates previous reports [28, 29]. LD infection is associated with increased membrane fluidity [30] which is restored after successive doses of Imipramine that improved antigen presentation ability. The workers further reported that the TNF- $\alpha$, IFN- $\gamma$ and iNOS activities were increased with concomitant decrease in IL-10 and Transforming GrowthFactor- $\beta$ (TGF- $\beta$ ) level in the Imipramine treated LD infected hamsters [22].

The mechanism of action of the drug Imipramine on Kala-azar patients infected with antimonyresistant Leishmania donovani $[\mathrm{Sb}(\mathrm{R}) \mathrm{LD}]$ has also been postulated [31]. The workers observed that Imipramine inhibits IL-10 production from $\mathrm{Sb}(\mathrm{R})$ LDinfected macrophages [Sb(R)LD-M $\varphi s$ ] and helps to accumulate surrogate antimonials. IL-10 driven nuclear translocation of c-Fos/ c-Jun is inhibited which is critical for enhanced multidrug resistance protein (MDR-1) expression. Histone deacetylase 11 inhibits acetylation of IL-10 promoter [32]. Imipramine up regulates Histone deacetylase 11 that leads to decrease in IL-10 production from $\mathrm{Sb}(\mathrm{R}) \mathrm{LD}-\mathrm{M} \varphi \mathrm{s}$. They observed that Histone deacetylase 11 does not interfere in IL-12 promoter activity but Imipramine induced decreased IL-10 level which in turn, allows optimal IL-12 production in Sb(R)LDM $\varphi$ s resulting in increased IL-12/IL-10 ratio. This skewing in Th1/Th2 ambience is crucial for halting disease progression.

\section{Sertraline}

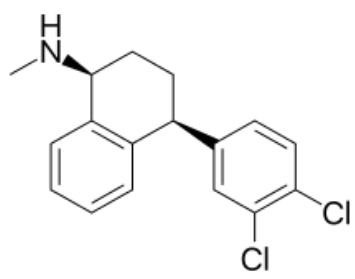

Sertaline belongs to selective serotonin reuptake inhibitor (SSRI) class of antidepressant. It is widely used for treating major depressive disorder (MDD), obsessive compulsive disorder (ODD), body dysmorphic disorder (BDD), posttraumatic stress disorder (PTSD), premenstrual dystrophy disorder (PMDD), panic disorder and social anxiety disorder [33].

Sertraline shows encouraging antifungal activities [34], antimicrobial [35], spermicidal and antitrichomonas[36], anticanceractivities[37]. It has also been observed that, Sertraline killed L.donovani promastigotes and amastigotes with IC50 value of $2.2 \mathrm{mg} / \mathrm{L}$ and $2.3 \mathrm{mg} / \mathrm{L}$ respectively[38]. Sertraline was also effective in removing parasite loads from spleen (72\%) and liver (70\%) in LD infected BALB/c mice [38]. This drug induced decline in cytoplasmic ATP levels and oxygen consumption rate in promastigotesindicates that promastigotes were killed by apoptosis [38].

\section{Ketanserin}

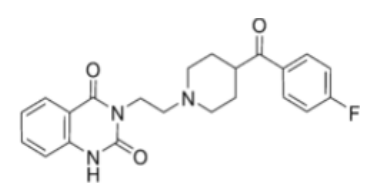

Ketanserin is clinically used for the treatment of arterial hypertension and vasopastic disorders [39]. It lowers blood pressure in essential hypertension as well as inhibits platelet aggregation particularly effective in older patients [40]. Ketanserin is a 5-HT2A/2C receptor antagonist with weak adrenergic receptor blocking properties [44, 40-41]. Ketanserin shows some affinity for alpha-1 receptors [41] which contributes to its antihypertensive effect.On the other hand, in receptor binding assays and autoradiography Ketanserin radioactively labeled with tritium $(3 \mathrm{H})$ is used as radio ligand for serotonin 5-HT2A receptor[42]. This radio labeling, in turn, assists in the study of the serotonin 5-HT2A receptor 
distribution in the brain [43]. The lethal effect of Ketanserin to the parasite was due to inhibition of HMGR. Hence, Ketanserin might be a useful choice for Kala-Azar therapy.

\section{Mianserin}

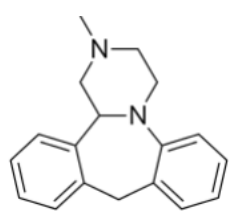

Mianserin belongs to the TCA therapeutic family but classified as a noradrenergic and specific serotonergic antidepressant (NaSSA). This drug acts as antidepressant, anxiolytic, hypnotic, antiemetic, orexigenic and antihistaminic effects [39]. Mianserin has been tried against treatment-resistant depression [45] and schizophrenia successfully reducing negative and cognitive symptoms [46-48].

Antileishmanial Activities of the AntiFungal Drugs:

\section{Amphotericin B}

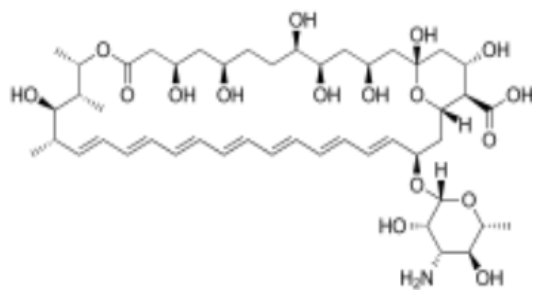

Amphotericin B is an antifungal medication used for serious fungal infections and leishmaniasis. ${ }^{[52]}$ The fungal infections it is used to treat include aspergillosis, blastomycosis, candida, coccidioidomycosis, and cryptococcosis. ${ }^{[53]}$ For certain infections it is given with flucytosine.$^{[53]}$ It is typically given by injection into a vein ${ }^{[52]}$ Common side effects include a reaction with fever, chills, and headaches soon after the medication is give, as well as kidney problems. Allergic symptoms including anaphylaxis may occur. ${ }^{[53]}$ Other serious side effects include low blood potassium and inflammation of the heart. ${ }^{[52]}$ It appears to be relatively safe in pregnancy. There is a lipid formulation that has a lower risk of side effects. ${ }^{[53]}$ It is in the polyene class of medications and works in part by interfering with the cell membrane of the fungus. ${ }^{\text {[52][53] }}$ Amphotericin B binds with ergosterol, a component of fungal cell wall, forming pores that cause rapid leakage of monovalent ions $\left(\mathrm{K}^{+}, \mathrm{Na}^{+}, \mathrm{H}^{+}\right.$and $\left.\mathrm{Cl}^{-}\right)$and subsequent fungal cell death. This is amphotericin B's primary effect as an antifungal agent. ${ }^{54][55]}$ It has been found that the amphotericin B/ergosterol bimolecular complex that maintains these pores is stabilized by Van der Waals interactions. ${ }^{[56]}$ Researchers have found evidence that amphotericin B also causes oxidative stress within the fungal cell, ${ }^{[57]}$ but it remains unclear to what extent this oxidative damage contributes to the drug's effectiveness. ${ }^{[56]}$ The addition of free radical scavengers or antioxidants can lead to amphotericin resistance in some species, such as Scedosporium prolificans, without affecting the cell wall.Two amphotericins, amphotericin A and amphotericin B, are known, but only B is used clinically, because it is significantly more active in vivo. Amphotericin A is almost identical to amphotericin $\mathrm{B}$ (having a double $\mathrm{C}=\mathrm{C}$ bond between the 27 th and 28th carbons), but has little antifungal activity. ${ }^{[57]}$

\section{Griseofulvin}<smiles>COC1=CC(=O)C[C@@H](C)[C@]12Oc1c(Cl)c(OC)cc(OC)c1C2=O</smiles>

Griseofulvin is antifungal medication used to treat a number of types of dermatophytoses (ringworm). ${ }^{[58]}$ This includes fungal infections of the nails and skin when antifungal creams have not worked. ${ }^{59]}$ It is taken by mouth. ${ }^{[1]}$ Common side effects include allergic reactions, nausea, diarrhea, headache, trouble sleeping, and feeling tired. It is not recommended in people with liver failure or porphyria. ${ }^{[58]}$ Use during or in the months before pregnancy may result in harm to the baby. ${ }^{[58][59]}$ Griseofulvin works by interfering with fungal mitosis. ${ }^{[58]}$ The drug binds to tubulin, interfering with microtubule function, thus inhibiting mitosis. It binds to keratin in keratin precursor cells and makes them resistant to fungal infections. The drug reaches its site of action only when hair or skin is replaced by the keratin-griseofulvin complex. Griseofulvin then enters the dermatophyte through energy-dependent transport processes and bind to fungal microtubules. This alters the processing for mitosis and also underlying information for deposition of fungal cell walls. 


\section{Flucytosine}<smiles>Nc1nc(=O)[nH]cc1F</smiles>

Flucytosine, also known as 5-fluorocytosine (5-FC), is an antifungal medication. It is specifically used, together with amphotericin B, for serious Candida infections and cryptococcosis. It may be used by itself or with other antifungals for chromomycosis. ${ }^{[1]}$ Flucytosine is used by mouth and by injection into a vein. ${ }^{[60][61]}$

Common side effects include bone marrow suppression, loss of appetite, diarrhea, vomiting, and psychosis. anaphylaxis and other allergic reactions occasionally occur. It is unclear if use in pregnancy is safe for the baby. ${ }^{[62]}$ Flucytosine is in the fluorinated pyrimidine analogue family of medications. It works by being converted into fluorouracil inside the fungal which then blocks its ability to make protein. ${ }^{[60]}$

\section{Conclusion}

Visceral Leishmaniasis (VL) or Indian Kala-azar is one of the neglected tropical diseases that show mortality worldwide.Current drugs are showing treatment failure due to unresponsiveness of the parasites for the prevailing drugs. The disease control strategy has become further complicated due to the complicated epidemiological picture i.e. involvement of other species (L. tropica) ${ }^{[61-63]}$ or even other genus (Leptomonas) ${ }^{[64]}$ with the disease. The drug suitable for L. donovani may not kill L. tropica or Leptomonas sp. HIV co infection also makes the picture further bleak ${ }^{[65-66]}$. Thus, present status of disease control strategy demands new promising drugs of cheaper prices which may combat both the responsive and unresponsive cases of VL. Current trend in chemo therapeutic drug discovery is aimed to search of some new purpose of putting an old drug for the treatment of another disease. Many drugs well used for other diseases, like Miltefosine for cancer and Amphotericin B for fungal infection, griseoflavin and flucytosine, were successfully used against Leishmaniasis. Four antidepessant drugs showed some promise in controlling experimental Leishmaniasis. This could be extrapolated to higher rank of study involving clinical trials. Present antileishmanial drug search indicates a future evolution of promising antidepressant drug groups, antifungal drugs groups effective against Leishmania sp.

\section{References}

[1].Paiva BR, et al. Detection and identification of Leishmania species in field-captured phlebotomine sandflies based on miniexon gene PCR. Acta Trop. 2006; 99:252-259.

[2].Croft SL and Coombs GH. Leishmaniasis-current chemotherapy and recent advances in the search for novel drugs. Trends Parasitol. 2003; 19:502-508.

[3].Assimina Z, et al. Leishmaniasis: An overlooked public health concern. Health Sci J. 2008; 2:196-205.

[4].Hide M, et al. Understanding Human Leishmaniasis: The need for an integrated approach in encyclopedia of infectious diseases book of microbiology. (ed by Michel T), John Wiley and Sons Inc, 2007; 87-107.

[5].Banuls A, et al. Leishmania and the leishmaniases: A parasite genetic updates and advances in taxonomy, epidemiology and pathogenicity in humans. Adv Parasitol. 2007; 64:1-109.

[6].Asford RW. The leishmaniases as model zoonoses. Ann Trop Med Parasitol. 1997; 91: 693701.

[7].Leishmaniasis: Epidemiology and access to medicines.

[8].Redhu NS, et al. Leishmaniasis-HIV co-infection: an emerging problem in India, AIDS. 2006; 20:1213-1215.

[9].Alvar J, et al. Leishmania and human immune-deficiency virus co infection: the first 10 years. Clin Microbiol Rev. 1997; 10: 298-319

[10]. Sundar S, et al. Failure of pentavalent antimony in visceral leishmaniasis in India: report from the center of the Indian epidemic. Clin Infect Dis. 2000; 31:1104-1107.

[11]. Sundar S. Drug resistance in Indian visceral leishmaiasis. Trop Med Int Health. 2001; 6: 849854.

[12]. Pandey BD, et al. Short Report: Release of Visceral Leishmaniasis after Miltefosine Treatment in Nepalese Patient. Am J Trop Med Hyg. 2009; 80: 580-582.

[13]. Srivastava $P$, et al. Unusual case of resistance to amphotericin B in visceral leishmaniasis in a region in India where leishmaniasis is not endemic, J Clin Microbiol. 2011; 49: 3088-3091.

[14]. Monzote L. Current treatment of Leishmaniasis: A review. The open Antimicrob Agents J. 2009; 1: 9-19.

[15]. Costa CHN, et al. Vaccine for the Leishmaniases: Proposals for a research agenda. PLoS Negl Trop Dis. 2011; 5: e943.

[16]. 16.Essentials of medical pharmacology by K.D. Tripathi seveth edition ,jaypee publication antidepressant pg no 454.

[17]. Malenka RC, et al. Ed, Molecular Neuropharmacology: A Foundation for Clinical Neuroscience (2nd ed.). New York: McGraw-Hill Medical. 2009; 4.

[18]. Guzman F. Serotonin (5-HT): receptors, agonists and antagonists. Available: www.pharmacologycorner.com.

[19]. Glennon RA, et al. Serotonin Recptor Subtypes and Ligands. American College of Neurophyscopharmacology. Archived from the original on 21 April 2008. Retrieved 2008-04-11.

[20]. Upadhyay SN. Serotonin Receptors, Agonists and Antagonists. Indian J Nucl Med. 2003; 18: 1-11. 
[21]. David E Golan. Principles of Pharmacology: The Pathophysiologic Basis of Drug Therapy. 2nd edition. LWW. 2008.

[22]. Harvey R and Champe P. Lippincott illustrated reviews: Pharmacology. 4th edition. LWW. 2009.

[23]. Yildiz A, et al. Mechanism of actions of antidepressants: beyond the receptors. Derlemeler/ Reviews. Bull ClinPsychopharmacol. 2002; 12: 194-200.

[24]. Mukherjee S, et al. Imipramine is an orally active drug against both antimony sensitive and resistant Leishmania donovaniclinical isolates in experimental infection. PLoS Negl Trop Dis. 2012; 6: e1987.

[25]. Zilberstein D, et al. Trycyclic drugs reduce proton motive force in Leishmania donovani promastigotes. Biochem Pharmacol;1990; 39: 935-940.

[26]. Benson TJ, et al. Rationally designed selective inhibitors of trypanothione reductase. Phenothiazines and related tricyclics As lead structure. Biochem J. 1992; 286: 9-11.

[27]. 27.Kubera M, et al. Stimulatory effect of antidepressants on the production of IL-6. Int Immunopharmacol, 2004; 4: 185-192.

[28]. Halliell WH. Cationic amphiphilic drug-induced phospholipidosis. Toxicol Pathol. 1997; 25: 53-60.

[29]. Evans AT and Croft SL. Antileishmanial actions of tricyclic neuroleptics appear to lack structural specificity. BiochemPharmacol. 1994; 48: 613-616.

[30]. Gottlieb E, et al. Mitochondrial membrane potential regulates matrix configuration and cytochrome c release duringapoptosis. Cell Death Differ. 2003; 10: 709-717.

[31]. Ly JD, et al. The mitochondrial membrane potential (deltapsi(m)) in apoptosis; an update. Apoptosis. 2003; 8: 115128.

[32]. Chakraborty D, et al. Leishmania donovani affects antigen presentation of macrophage by disrupting lipid rafts. $\mathrm{J}$ Immunol.2005; 175: 3214-3224.

[33]. Mukherjee S, et al. Imipramine exploits histone deacetylase 11 to increase the IL-12/IL-10 ratio in macrophages infected with antimony-resistant Leishmania donovani and clears organ parasites in experimental infection. J Immunol. 2014; 193: 4083-4094.

[34]. Villagra A, et al. The histone deacetylase HDAC11 regulates the expression of interleukin 10

[35]. and immune tolerance. NatImmunol. 2009; 10: 92-100.

[36]. Compton SN, et al. Sertraline in children and adolescents with social anxiety disorder: an open trial. J Am Acad ChildAdolesc Psychiatry. 2001; 40:564-571.

[37]. Lass-Flori C, et al. Antifungal properties of selective serotonin reuptake inhibitors against Aspergillus species invitro. JAntimicrob Chemother. 2001; 48: 775-779.

[38]. Munoz-Bellido JL, et al. Antimicrobial activity of psychotropic drugs: selective serotonin reuptake inhibitors. Int J AntimicrobAgents. 2000; 14: 177-180.

[39]. Kumar VS, et al. The spermicidal and antitrichomonas activities of SSRI antidepressants. Bioorg Med Chem Lett. 2006;16: 2509-2512.

[40]. Tuynder M, et al. Translationally controlled tumor protein is a target of tumor reversion. Proc Natl Acad Sci USA. 2004; 101:15364-15369.

[41]. Palit P and Ali N. Oral therapy with sertraline, a selective serotonin reuptake inhibitor, shows activity against Leishmaniadonovani. J Antimicrob Chemother. 2008; 61: 1120-1124.

[42]. Person B, et al. Clinical Pharmacokinetics of ketanserine. Clin Pharmacokinet. 1991; 20: 263-279.

[43]. National Institute of Health: National Library of Medicine, Medical Subject Headings.

[44]. MeSH. MeSH Descriptor Data, 2006.

[45]. Bruton, LB, Lazo JS and Parker, KL (Eds) Goodman and Gilman's the pharmacological basis of therapeutics. 11th edition.Newyork: McGraw-Hill, 2005.

[46]. Eickhoff SB, et al. Analysis of neurotransmitter receptor distribution patterns in the cerebral cortex. Neurolmage. 2007; 34:1317-1330.

[47]. Pazos A, et al. Serotonin receptors in the Human Brain-IV. Autoradiographic mapping of serotonin-2 receptors. Neuroscience. 1987; 21: 123-139.

[48]. Singh S, et al. Ketanserine, an antidepressant, exerts its antileishmanial action via inhibition of 3-hydroxy-3methylglutarylcoenzyme A reductase (HMGR) enzyme of Leishmania donovani. Parasitol Res. 2014; 113: 21612168.

[49]. Ferreri M, et al. Benefits from mianserin augmentation of Fluoxetine in patients with major depressive nonresponders tofluoxetine alone. Acta Psychiatr Scand. 2001; 103: 66-72.

[50]. Poyurovsky M, et al. Effect of the 5-HT2 antagonist mianserin on cognitive dysfunction in chronic schizophrenia patients:an add-on, double-blind placebo-controlled study. Eur Neuropsychopharmacol. 2003; 13:123-128.

[51]. Shiloh R, et al. Mianserin or placebo as adjuncts to typical antipsychotics in resistant schizophrenia. Int Clin Psychopharmacol.2002; 17: 59-64

[52]. Mizuki Y, et al. Effects of mianserin on negative symptoms in schizophrenia. Int Clin Psychopharmacol. 1990; 5: 83-95.

[53]. Control of the leishmaniasis: report of a meeting of the WHO Expert Committee on the Control of Leishmaniases (PDF). World Health Organization. March 2010. pp. 55, 88, 186. ISBN 9789241209496.

[54]. "Amphotericin B". The American Society of Health-System Pharmacists. Retrieved Jan 1, 2015.

[55]. WHO Model Formulary 2008 (PDF). World Health Organization. 2009. p. 145.

[56]. ISBN 9789241547659. Retrieved 8 December 2016. 
Journal of Advance Research in Pharmacy and Biological Science (ISSN: 2208-2360)

[57]. Walker, S. R. (2012). Trends and Changes in Drug Research and Development. Springer Science \& Business Media. p. 109. ISBN 9789400926592.

[58]. "WHO Model List of Essential Medicines (19th List)" (PDF). World Health Organization. April 2015. Retrieved 8 December 2016. 